\title{
Caracterización de la fuerza laboral en la cadena productiva de las frutas - Uvilla (Physalis peruviana)
}

\section{Characterization of the labor force in the productive chain of fruits -Golden Berry (Physalis peruviana)}

\author{
MSc, María Dolores Guamán Guevara ${ }^{1}$ \\ md.guaman@uta.edu.ec \\ MSc, William Fabián Teneda Llerena ${ }^{2}$ \\ wf.teneda@uta.edu.ec \\ MSc, Víctor Manuel Reyes Mayorga ${ }^{3}$ \\ Vikthorr777@gmail.com \\ MSc, Jonathan Alejandro Jarrin Guayanay ${ }^{4}$ \\ jjarrin6592@uta.edu.ec
}

Recibido: 1/04/2019; Aceptado: 1/06/2019

\begin{abstract}
RESUMEN
La situación social del campo ecuatoriano se caracteriza por altos niveles de pobreza, sin embargo, existen excepciones. En efecto, algunos cultivos dan al trabajador mejores condiciones que otros. Estudios previos hacen referencia al caso de los cultivos transitorio, entre otros la uvilla, en los cuales el trabajador tiene acceso seguridad social y empleo estable. La contribución de la agroindustria de la uvilla al proceso de desarrollo social de las comunidades pertenecientes a sus áreas de influencias es el objetivo de este artículo. En este análisis se incluyeron variables relacionadas con generación de empleo, condiciones de vida en ingreso de los trabajadores. Los principales hallazgos de este estudio son 1) la uvilla tiene gran capacidad de generación de empleos; 2) los municipios relacionados con la obtención de la uvilla tienen mejores condiciones de vida que las de otros localizados en las mismas áreas que no se dedican a esta actividad, y 3) los trabajadores del sector de uvilla ecuatoriano que en general son poco calificados son bien remunerados. La presente investigación basada en estudios bibliográficos de fuentes primarias y secundarias definirá los factores de los individuos dentro de las cadenas de producción de la uvilla, revisar información bibliográfica en revistas indexadas y libros sobre las variables que se están investigando, determinar en base a investigaciones la incidencia de producción de la uvilla en países de la zona andina.
\end{abstract}

Palabras Clave: uvilla, desarrollo social, empleo, fuerza laboral, condiciones de vida

\footnotetext{
1 Universidad Técnica de Ambato, Ambato, Ecuador.

2 Universidad Técnica de Ambato, Ambato, Ecuador.

3 Universidad Técnica de Ambato, Ambato, Ecuador.

4 Universidad Técnica de Ambato, Ambato, Ecuador.
} 


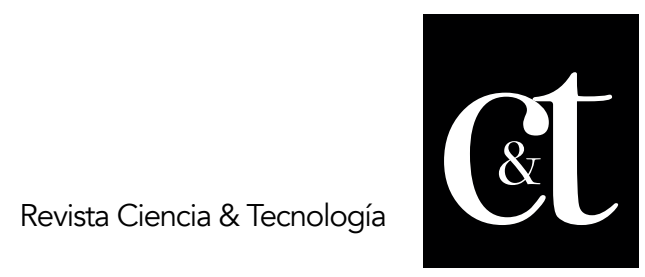

No. 23, 31 de julio de 2019

ISSN impreso: 1390 - 6321

ISSN online: 2661 - 6734

\begin{abstract}
The social situation of the Ecuadorian countryside is characterized by high levels of poverty, however, there are exceptions. In effect, some crops give the worker better conditions than others. Previous studies make reference to the case of transitory crops, among others the grapevine, in which the worker has access to social security and stable employment. The contribution of the uvilla agroindustry to the process of social development of the communities belonging to its areas of influence is the objective of this article. In this analysis variables related to employment generation, living conditions in workers' income were included. The main findings of this study are 1) the uvilla has great capacity to generate jobs; 2 ) the municipalities related to the obtaining of the uvilla have better living conditions than those of others located in the same areas that are not dedicated to this activity, and 3) the workers of the Uvilla sector of Ecuador that in general are poorly qualified are well paid. The present investigation based on bibliographic studies of primary and secondary sources will define the factors of the individuals within the production chains of the uvilla, review bibliographic information in indexed journals and books on the variables that are being investigated, determine based on research the incidence of uvilla production in countries of the Andean region.
\end{abstract}

Keywords: uvilla, social development, employment, labor force, living conditions

\title{
Introducción
}

La problemática en el estudio en la cadena de las frutas especificadamente de la uvilla está relacionado a la limitada información sobre el manejo de campo, pos-cosecha y comercialización por lo que genera irregularidad en los datos referenciales actualizados, no hay una secuencia en la producción regular por lo cual existe disparidad productiva entre cada año, uso de sistemas tradicionales pocos productivos comparados con las tecnificaciones actuales implantadas en otros países, la poca generación de tecnología y asesoramiento técnico que reciben los productores afecta directamente al producto final, Las restricciones de los productos frutícolas afectan la cantidad, calidad y continuidad limita las oportunidades comerciales nacionales e internacionales, carecer de un sistema directo de comercialización encare la producción lo que disminuye los beneficios (Altamirano, 2010).

Una de las prioridades en la elaboración de un artículo científico es la necesidad de encontrar información relevante que ayude al buen funcionamiento del proyecto de investigación que se esté realizando. La revisión científica tiene un sólo propósito, informar el resultado de una investigación Es importante tomar en cuenta que la revisión de la literatura se maneja como un conjunto de técnicas que forman parte de la metodología de la investigación científica y que no se limita a una recopilación desordenada de la información. Es uno de los puntos de arranque para la elaboración de un artículo científico, libro, tesis, etc. 
Muchas veces se revisan investigaciones en las cuales las referencias bibliográficas están desactualizadas, el resumen no concuerda con el desarrollo de la investigación, la editorial no es confiable, entre otros datos que sólo un buen conocimiento y aplicación de técnicas de revisión de lectura nos ayudará a poder discernir y valorar la importancia de una información.

\section{Desarrollo}

En este sentido el objetivo de este artículo es brindar una guía simplificada para la revisión de literatura científica como paso previo para el desarrollo de la investigación.

\section{Tabla 1. Categorización de la empresa.}

\begin{tabular}{|l|l|l|l|l|l|l|}
\hline $\begin{array}{l}\text { Categorización } \\
\text { Empresarial }\end{array}$ & Nr_Directivos & Nr_Administración & Nr_Producción & Nr_Otros & $\begin{array}{l}\text { Total } \\
\text { personas } \\
\text { ocupadas }\end{array}$ & $\begin{array}{l}\text { Total } \\
\text { Personal } \\
\text { ocupado } \\
\%\end{array}$ \\
\hline Grande & 7525 & 99383 & 274681 & 80879 & 462468 & $46 \%$ \\
\hline Mediano & 8197 & 39638 & 130312 & 48256 & 226403 & $23 \%$ \\
\hline Micro & 34336 & 32331 & 26968 & 14613 & 108248 & $11 \%$ \\
\hline Pequeña & 16521 & 38217 & 99798 & 43977 & 198513 & $20 \%$ \\
\hline Total general & 66579 & 209569 & 531759 & 187725 & 995632 & $100 \%$ \\
\hline
\end{tabular}

Fuente: INEC, 2017.

Elaborado por: Elaboración propia.

La importación del personal en las cadenas de producción radica en la productividad, está fuertemente relacionada las capacidades físicas e intelectuales de cada empelado ya que mientras más capacitado este un empleado mejor sabrá manejar los recursos con los que cuenta. El proceso de aprendizaje es continuo y sistemático para enseñar u optimizar las habilidades de las personas en todos los niveles de la empresa (Campuzano, Ziadet, \& Echeverria, 2016).

Partiendo de que la productividad es la habilidad para producir más y mejores con iguales o menores recursos, obteniendo más producción de cada unidad de capital y trabajo que se aporta al sistema económico, es necesaria la capacitación para el desarrollo de las habilidades en todos los niveles, desde los operativos hasta los mandos gerenciales. En cuestión de la capacitación de liderazgo se le proporcionan experiencias educativas diseñadas para mejorar su eficacia como líder (Alles, 2015).

El personal como capital humano dentro de las cadenas de producción está en constante desarrollar y/o perfeccionar las aptitudes relacionado estrechamente con el área cognoscitiva, con el propósito de prepararle para que se desempeñe correctamente en un puesto específico de trabajo permitiendo una mejor relación con el medio y los participantes presentes (Mejía, Bravo, \& Montoya, 2013). 


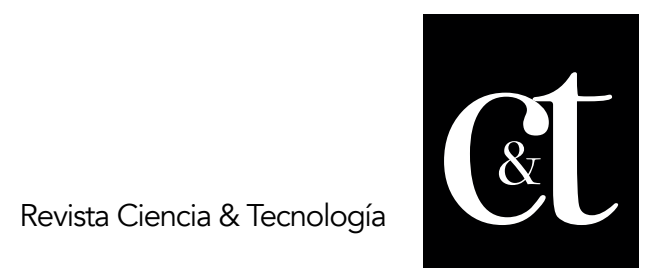

No. 23, 31 de julio de 2019

ISSN impreso: 1390 - 6321

ISSN online: 2661 - 6734

Es un conjunto de sistemas constituidos por actores interrelacionados y por una sucesión de operaciones de producción, transformación y comercialización de un producto o grupo de productos en un entorno determinado. El análisis de cadenas es una herramienta de análisis que permite identificar los principales puntos críticos que frenan la competitividad de un producto, para luego definir e impulsar estrategias concertadas entre los principales actores involucrados, interrelacionados y sucesión de operaciones de producción, transformación y comercialización de un producto/s en un entorno determinado. Todo este conjunto de actores, acciones, relaciones, transformaciones y productos es lo que se conoce como cadena productiva (Gálvez, 2006).

La finalidad de las cadenas de productividad se centra en conocer en detalle el funcionamiento de un proceso productivo desde el punto de vista tecnológico y económico, definir las posibilidades reales de mantener o generar competitividad, evaluar el impacto de los cambios en el entorno, estudiar la influencia de la situación económica nacional e internacional, definir agendas de trabajo conjuntas entre los agentes económicos que participan en la cadena (Gonzalez-Corzo, 2015).

Las características de las cadenas productivas presentan una finalidad que es la trasformación del producto, el cual pasa por un proceso de producción, transformación o intercambio hasta llegar al consumidor final. La caracterización de las cadenas productivas posee 2 esquemas el tradicional y del esquema moderno, estos varían en función del giro de las empresas que forman parte de la cadena, siendo industrial, comercial o de servicio (Tomta \& Chiatchoua, 2009).

Así, el enfoque tradicional de la cadena productiva se centra en una serie de procesos consecutivos, lentos, análogos, pocos dinámicos y secuencial, constituida por fases como son: fabricación, revisión y comercialización (Gottret \& Lundy, 2007).

Por otro lado, enfoque moderno más ágil y adaptable por lo que se centra a un crecimiento organizacional, en que los diferentes actores internos (actores directos: producción transformación comercialización y consumo) y externos (actores indirectos: investigación, capacitación, asistencia técnica y proveedores de energía) presentes en la cadena productiva intervienen colaborando entre sí, en los diferentes procesos (Gottret \& Lundy, 2007).

Para realizar una aproximación del flujo de la cadena productiva de la uvilla, esta es la identificación breve de todas las etapas por las que pasa el producto desde la producción hasta el consumidor final. Este bosquejo se construye en base en base de los conocimientos que tiene el trabajo sobre la cadena (Salazar \& Van der Heyner, 2004). 


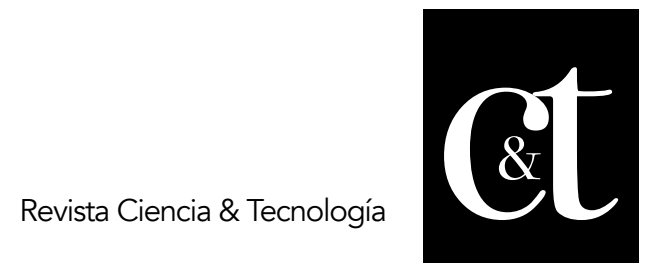

No. 23, 31 de julio de 2019

ISSN impreso: 1390 - 6321

ISSN online: 2661 - 6734

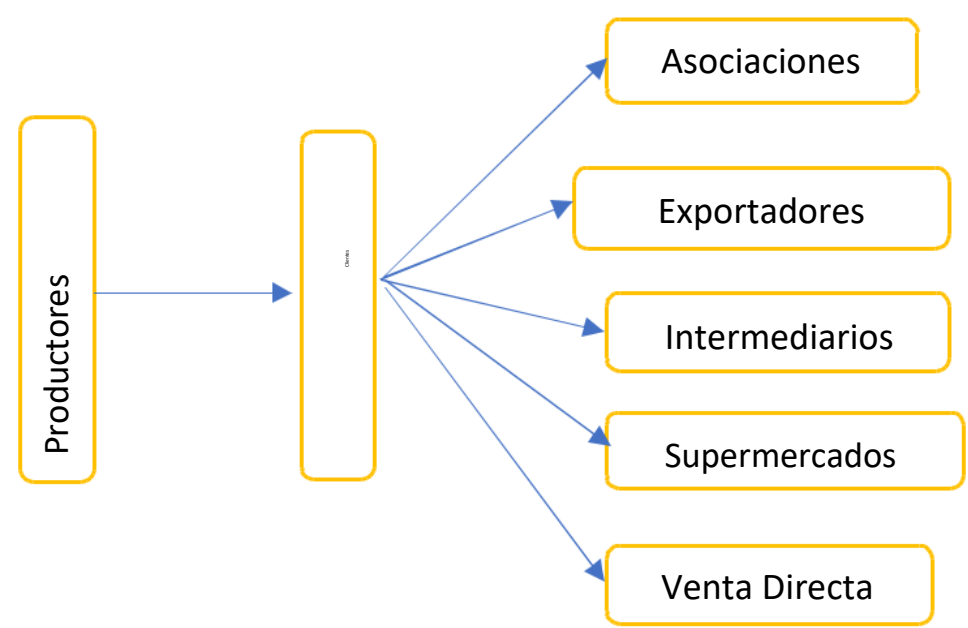

Gráfico 1. Actores que intervienen en la cadena de producción Fuente: elaboración propia

Actores directos: Son aquello que, en algún momento, son dueños del producto (Salazar \& Van der Heyner, 2004).

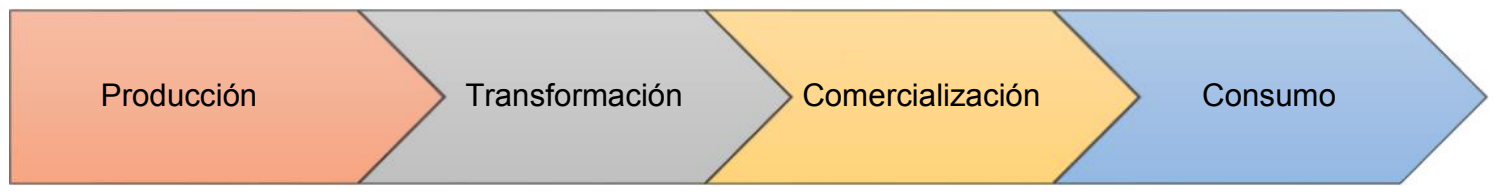

\section{Gráfico 2. Actores directos}

Fuente: Elaboración propia

Actores indirectos: Son los que brindan insumos y/o servicios de apoyo a la cadena, pero en ningún momento tienen la posesión del producto (Salazar \& Van der Heyner, 2004).
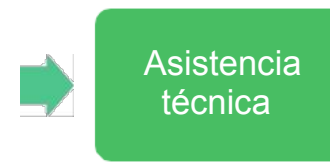

\section{Gráfico 3. Actores indirectos}

Fuente: Elaboración propia 


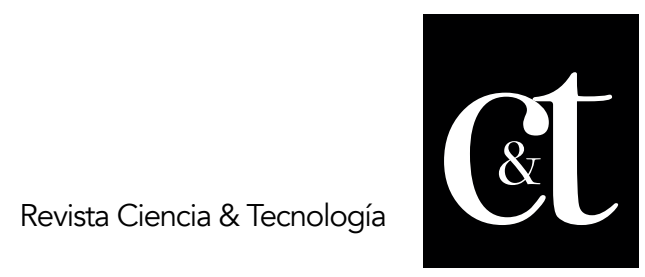

No. 23, 31 de julio de 2019

ISSN impreso: 1390 - 6321

ISSN online: 2661 - 6734

Alianza entre productores, bancos, ONG y comercializadores para la producción y comercialización de la uvilla en Tungurahua (Salazar \& Van der Heyner, 2004).
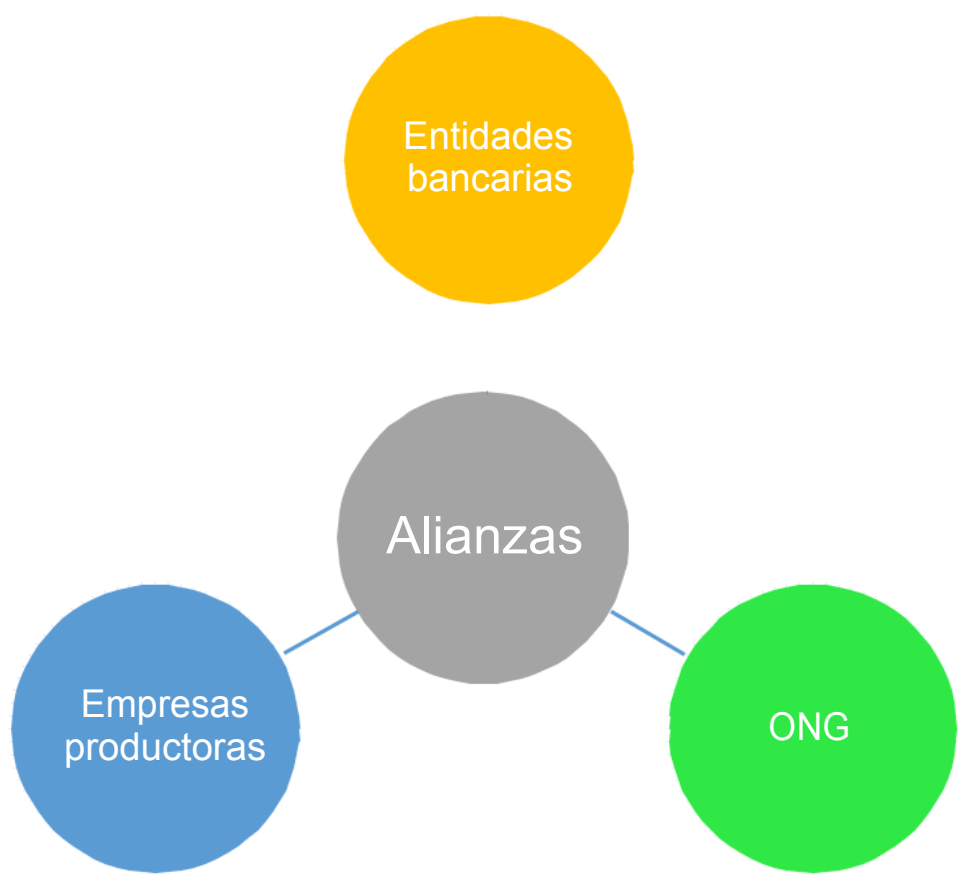

Gráfico 4. Alianzas de producción de la cadena de producción Fuente: Elaboración propia

La productividad y la sostenibilidad de una cadena frutícola se relaciona directamente con las características específicas como son la sociales, climáticas, políticas, culturales, zona en la que se ubica, etc. Los elementos comunes presentes son la asociatividad de los pequeños productores y sus familias puedan integrarse en el mercado, la unión hace la fuerza y es un elemento imprescindible para la insertarse en una cadena de manera sostenible, mejora de las capacidades técnicas para producir más y mejor incluyendo formación empresarial y de gestión para enfrentar procesos de comercialización asociativa siendo una inversión clave a largo plazo estructuración de servicios de apoyo tales como crédito, asistencia técnica, provisión de insumos, etc., que tienen un papel relevante dentro de las cadenas y su mejoramiento (Tamayo \& Cepeda, 2017). 


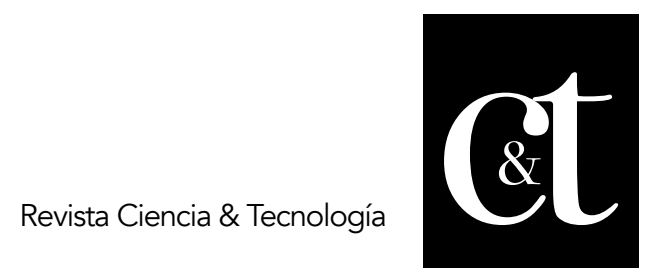

No. 23, 31 de julio de 2019

ISSN impreso: 1390 - 6321

ISSN online: 2661 - 6734

En el proceso de producción el hombre no sólo actúa sobre la naturaleza que le rodea, sino que desarrolla, además, su experiencia productiva, sus hábitos de trabajo; la fuerza laboral es la capacidad del hombre para trabajar. Es el conjunto de fuerzas físicas y conocimiento de que el hombre dispone y que utiliza en el proceso de producción de los bienes materiales, siendo la condición fundamental de la producción en toda sociedad (Torres \& Jaramillo, 2014).

El concepto de fuerza de trabajo aparece por primera vez de la pluma del filósofo alemán Karl Marx, en su obra más reconocida, El Capital, editada en el año 1867. En la mencionada obra, Marx propone como ideal el logro de una sociedad en la que no existan diferenciaciones de clases. En este sentido el proceso productivo, sus fuerzas de producción y las relaciones productivas se transforma en un bien social (Añez, 2015).

De lado opuesto se presenta el capitalismo que se ha apropia del trabajo, es decir, compra la mano de obra a través de una suma de dinero que se le abona al trabajador. La fuerza de trabajo es una mercancía que produce el obrero y que paga el capitalista, el valor que se paga se calcula sobre el tiempo que se invierte para producirla (Torres \& Jaramillo, 2014).

Con la evolución de la sociedad va ligada conjuntamente la de las empresas y los cambios desde procesos de producción hasta los métodos de administración. Es en este último punto que la fuerza laboral adopta otro nivel de significancia. Así surge la gestión del talento y los recursos humanos. Esta nueva ciencia evolucionan de manera rápida para ofrecer, junto con la psicología organizacional, alta competitividad y productividad a las empresas y mayor motivación para los empleados, centrándose en un eje más operativa en la que los trabajadores de recursos humanos se dedicaban sobre todo a administrar el personal, ejecutar procesos de selección y gestionar nóminas. Conduce a una vertiente mucho más estratégica orientada a la gestión del talento, rescatando una visión más completa de la fuerza de trabajo. Si deja de lado a los avances tecnológicos, algunas de las funciones operativas del departamento de recursos humanos han dejado de ser hechas por personas, para pasar a estar en manos de programas informáticos específicos, actualmente y se demuestra que el progreso informático también puede ser una ayuda estratégica (Gasparini \& Marchionni, 2015).

El cliente interno es el elemento dentro de una empresa presente en grupos, áreas o departamento, que toma el resultado o producto de un anterior proceso como recurso para realizar su propio proceso. Después, entregará su resultado a otro trabajador de la empresa para continuar con el proceso hasta acabarlo y ponerlo a venta y lo adquiera el cliente externo y así todos los actores que intervienen en un proceso generador de resultados (productos o servicios), que se entregan a un cliente. El cliente interno utilizará los productos resultantes del proceso anterior como entrada (recursos) para su propio proceso. A su vez, éste último elaborará las salidas oportunas (productos) que serán utilizadas por otro cliente interno, o que llegarán hasta el mercado, dirigidas a clientes externos (Guamán, Caisa, Acosta, Miranda, \& Fidel, 2017). 


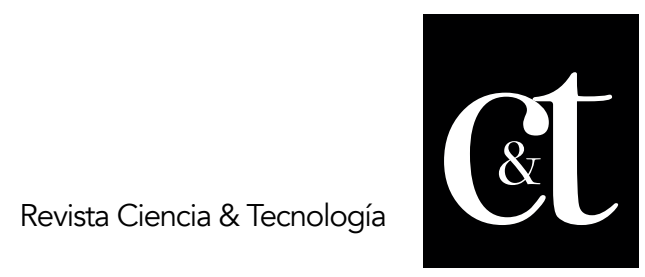

No. 23, 31 de julio de 2019

ISSN impreso: 1390 - 6321

ISSN online: 2661 - 6734

Las opiniones y puntos de vista que tiene los clientes internos deben ser tomados en cuenta para la formulación de objetivos y estrategias. La meta de toda organización es dar un excelente servicio para lo cual el personal debe entender sus metas, valores, tareas y responsabilidades dentro de un marco que cubra la comunicación efectiva, capacitación permanente, agradable ambiente de trabajo, participación activa y constante, buen trato, justa remuneración, garantía de permanencia en el trabajo y reconocimiento de logros (Guamán, Caisa, Acosta, Miranda, \& Fidel, 2017).

Con base en lo establecido en los anteriores puntos, se sumará para la cultura general de la cadena de producción la conceptualización de mercado corporativo interno, que consiste en establecer un plan de marketing de puertas adentro de la empresa, con el objetivo de fidelizar a todos los colaboradores de la entidad (clientes internos) y mejorar la productividad de sus relaciones. No presenta como ventajas el crear una filosofía propia, que valoren todos los colaboradores de la empresa como un valor añadido en su relación con la empresa. El definir una cultura empresarial propia en el mercado de trabajo es con el fin de establecer hábitos de trabajo que permitan obtener mayor productividad con la misma fuerza laboral; de este modo, se logra una estabilidad y confianza en los empleados, lo que repercute directamente en su motivación. Es así como se promueve la comunicación entre todos los sectores de la compañía, poder hacer frente a las situaciones de crisis con mayor efectividad y rapidez (Guamán, Caisa, Acosta, Miranda, \& Fidel, 2017).

La manufactura, agricultura, y ganadería mantiene un relación directa con los recursos naturales propios de cada país y entre los productos exóticos apetecidos por los mercados internacionales como frutas sudamericanas, se considera a la uvilla como un producto cuyo cultivo es una alternativa de inversión por sus costos bajos. Es de sabor agridulce y propiedades nutricionales y pertenece al género Physalis Peruviana que posee características únicas y distintivas como: forma redonda ovoide, del tamaño de una uva grande, con piel lisa, brillante y de color amarillo dorado - naranja; o verde según la variedad, apetecidas por el mercado americano y europeo (Coronel, 2016).

Los valles bajos andinos, desde Ecuador hasta Chile tienen temperaturas de $18 \mathrm{C}^{\circ} \mathrm{y}$ poseen condiciones agroecológicas para producir uvillas con una coloración más intensa, mayor contenido de azucares y almidones, lo que hace que el fruto sea menos ácido comparada con la procedente de Kenia y Sudáfrica. Pequeños y medianos productores en el Ecuador de la Uchuva (o uvilla), realizan esta actividad fruticultora en la Sierra Norte entre los 2.00 a 3.000 msnm. Según el Banco Central de Ecuador, se exportó 104,7 ton., por un valor FOB (free on board) de US $\$ 407.640$, con precio de US $\$ 3,57 / \mathrm{kg}$. Los países a los que mayormente se exporta son: Holanda con el $43 \%$ del total, seguido por España, Alemania, Canadá, Reino Unido, Suecia, Bélgica, Suiza e Italia. Se destaca a Imbabura por su sistema de producción tecnificada y Tungurahua que posee una temperatura media de $25 C^{\circ}$ (Coronel, 2016). 
Tabla 2. Áreas representativas para la producción de uvilla

\begin{tabular}{llll}
\multicolumn{1}{c}{ Sitios } & \multicolumn{1}{c}{$\begin{array}{c}\text { Altura } \\
(\mathbf{m s n m})\end{array}$} & $\begin{array}{l}\text { Temperatura } \\
\left(\mathbf{C}^{\circ}\right)\end{array}$ & $\begin{array}{l}\text { Precipitación } \\
\mathbf{( m m )}\end{array}$ \\
\hline Atuntaqui & 2.350 & 15.5 & 612.2 \\
Otavalo & 2.556 & 14.5 & 822.2 \\
\hline Yaruqui & 2.417 & 15.7 & 1.100 \\
Huacho & 2.700 & 13.2 & 700.0 \\
Pujilí & 2.770 & 13.5 & 700.0 \\
Quero & 2.950 & 13.0 & $\mathrm{~N} . \mathrm{D}$. \\
Pelileo & 2.800 & 13.5 & 600.0 \\
Patate & 2.360 & 16.2 & 596.2 \\
Gualaceo & 2.360 & 16.5 & 741.4 \\
Fuente: PROEXANT. & & \\
Elaborado por: Elaboración propia.
\end{tabular}

Dentro de las cadenas de producción, la medición estratégica del talento humano se reconoce como activo intangible de la organización. Los estudios sobre la correlación de las prácticas del talento con los resultados financieros de la empresa contribuyen a generar conciencia sobre la importancia estratégica del talento humano (Gutiérrez, 2013).

¿Cómo el área de Recursos Humanos puede aportar a la productividad de las empresas? Esta es una de las preguntas clave que ha ganado relevancia en los últimos años. Investigaciones recientes presentan algunos hábitos empresariales que impactan negativamente en la productividad. Son actividades como reuniones extensas sin objetivos claros, jornadas y actividades fuera del horario laboral, imposibilidad de construir y sostener acuerdos entre colaboradores, errores de comunicación que generan reprocesos y costos a la empresa, poca capacidad de ordenar el tiempo, entre otros (Olivos, Orue, Martínez, Moreno, \& Nava, 2015).

La medición de la contribución estratégica de la fuerza laboral a través de índices de calidad vida permite orientar la medición hacia los factores críticos de éxito que impulsan los resultados del negocio. Ejemplo: índice de hacinamiento, tipo casa, caminos, educación, servicios básicos, etc. (Gasparini \& Marchionni, 2015).

La mejor manera que tiene una empresa de generar valor es a través del trabajo de sus empleados, por lo cual el valor agregado por persona y retorno sobre la inversión, permiten la medición en la generación de valor para orientar las decisiones de inversión en talento humano, estas mediciones se realizan a nivel global de la empresa o unidad de trabajo, incluso a nivel de empleados individuales. 


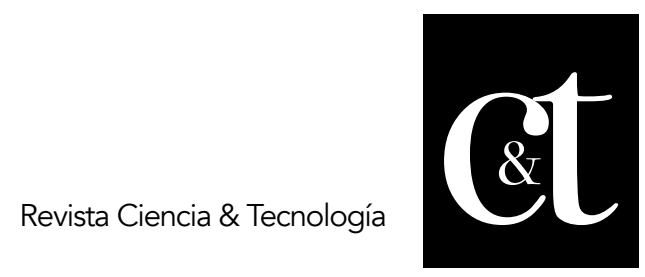

No. 23, 31 de julio de 2019

ISSN impreso: 1390 - 6321

ISSN online: 2661 - 6734

Los directivos de la empresa, entonces, tienen un rol de socio de negocio, como orientador y contribuidor directo a los resultados de generación de valor del negocio siendo el factor clave del éxito empresarial. Esto es especialmente valioso para las pequeñas y medianas empresas (pymes); por tanto, la atención a los recursos humanos en la pyme es fundamental como valor competitivo (Gelabert, 2014).

Dentro del proceso de la cadena de producción, los mayores aportes son de los trabajadores, los verdaderos estrategas empresariales que buscan el mejoramiento o de cambio. Se debe contar con los recursos humanos ya que ellos son un factor que puede lograr que un plan de acción tenga éxito. Un equipo de trabajo bien planificado y motivado resulta en un correcto manejo de los productos y una buena atención al cliente. El proceso de fidelización (clientes satisfechos que nos vuelven a comprar) es al mejor carta de presentación ante el mercado (Simanca, Montoya, Bernal, \& A. Bernal, 2015).

El crecimiento del Ecuador en los mercados internacionales debe ser un modelo basándose en dar la importancia necesaria a las cadenas productivas para el desarrollo y usándolas como herramientas de análisis. Estas permiten identificar los principales puntos críticos que frenan la competitividad de un producto, para luego definir e impulsar estrategias concertadas entre los principales actores involucrados, estos últimos vinculándose entre sí para llevar el producto de un estado a otro, desde la producción hasta el consumo. La estructura y dinámica de todo este conjunto de actores, acciones, relaciones, transformaciones y productos (Gálvez, 2006).

La finalidad que se busca en las cadenas de productividad se centra en conocer en detalle el funcionamiento del proceso productivo desde la perspectiva tecnológico como económico, identificar la factibilidad de mantener o generar competitividad nacional e internacional, evaluación de impacto de los cambios en el entorno y su influencia de la situación económica nacional e internacional, elaboración de agendas de trabajo conjuntas entre los agentes económicos que participan en la cadena (Coronel, 2016).

Actualmente en el Ecuador, en los últimos años se ha priorizado a sus cadenas productivas, elaborando plataformas con información y soporte (plataforma + unidad técnica de gestión) que cumplirán el rol de integrador de la industria ecuatoriana y potenciador de la misma, aumentando la competitividad de la cadena y su producto final. Se facilita así la integración de productores aislados a cadenas existentes para acceder a nuevos mercados (Peiró, 2015). Ese conjunto de actividades tiene como objetivo mejorar los niveles de encadenamiento económico y articulación económica productiva mediante el mejoramiento de la calidad, disponibilidad y flujos de la información de mercados, monitoreando la evolución de la balanza comercial para detectar oportunidades de sustitución estratégica de importaciones con la implementación base de datos de producción nacional, integrando todas las instituciones estatales de apoyo productivo y otras estratégicas tales como: 


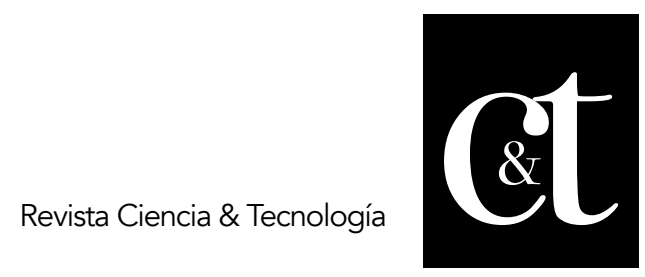

No. 23, 31 de julio de 2019

ISSN impreso: 1390 - 6321

ISSN online: 2661 - 6734

El Ministerio de Industrias y Productividad, Ministerio Coordinador de Producción Empleo y Competitividad, Servicio de Rentas Internas, Ministerio de Comercio Exterior, instituciones financieras, de cooperación internacional, entre otros.).

En los últimos 2 años, en Tungurahua, gracias a la colaboración del Observatorio Económico de la Universidad Técnica de Ambato, se determinó que entre los años 2016 y 2017 se crearon 7.000 nuevas plazas de trabajo, fruto del trabajo conjunto de los sectores productivos, la estabilidad política, el otorgamiento de créditos y la apuesta en marcha de nuevo emprendimientos, dando una media de entre 40 y 100 personas adicionales para mejorar su producción en cada sector (Jumbo, 2018).

Tungurahua es provincia que se caracteriza por articular su desarrollo de forma conjunta, vinculando todos los sectores productivos privados y públicos en ámbitos, como el económico, social, ambiental, educativo, de investigación, riego y muchos otros aspectos, potenciando la vocación empresarial, agrícola y comercial. Se evidencia así con resultados en este año a las empresas más importantes de fabricación de carrocerías, el $80 \%$ de la producción nacional de calzado y 700 negocios de textiles a nivel nacional. Partiendo del ejemplo realizado en Tungurahua, cada provincia tiene su vocación productiva y sus particularidades (Jumbo, 2018).

El Gobierno Provincial ha enfatizado sus esfuerzos para que los productores entren en un mercado competitivo que constituya la reactivación productiva, incrementado los ingresos económicos que generen las tareas agrícolas y ganaderas. Se asegura la seguridad alimentaria, mejorando la calidad de los productos, para lo cual se ha plateando una estrategia agropecuaria como un instrumento que busca aportar al desarrollo sostenible del sector productivo. Se implementaron nuevas tendencias de desarrollo agropecuario para apoyar a los agricultores de los nueve cantones de la provincia, buscando que los productores comercialicen sin intermediarios y con precios competitivos, de forma asociativamente junto con las instituciones como el Gobierno Provincial de Tungurahua, que acompañan con asistencia técnica y capacitación de manera mancomunada (Tungurahua, 2017).

\section{Materiales y Método}

Como metodología de la investigación se denomina el conjunto de procedimientos y técnicas que se aplican de manera ordenada y sistemática en la realización de un estudio que va a determinar la manera en que el investigador recaba, ordena y analiza los datos obtenidos (Coutintho, 2014).

Asimismo, como metodología de la investigación se denomina la parte de un proyecto en que son expuestos y descritos los criterios adoptados en la elección de la metodología de trabajo y las razones por las cuales se considera que dichos procedimientos son los más pertinentes para abordar el objeto de estudio, etc. (Coutintho, 2014). 


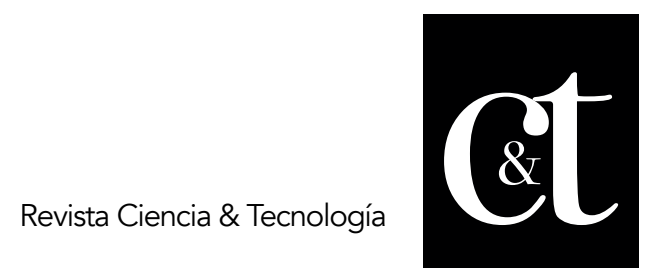

No. 23, 31 de julio de 2019

ISSN impreso: 1390 - 6321

ISSN online: 2661 - 6734

En un proceso de investigación, la metodología es una de las etapas en que se divide la realización de un trabajo (Paz, 2014). En ella, el investigador o los investigadores deciden el conjunto de técnicas y métodos que emplearán para llevar a cabo las tareas vinculadas a la investigación (Sabino, 2014).

El proceso es estable, convencional, con criterios estandarizados que permiten que el conocimiento sea comunicable en diferentes campos disciplinares, contextos y regiones del planeta. Es el idioma universal de la ciencia que posibilita el avance en todos los campos, el intercambio y transferencia de tecnología, el consenso y el trabajo multidisciplinario como tal esencial para el avance del conocimiento. La investigación científica es por su naturaleza un conocimiento de tipo instrumental es un saber hacer. La investigación está vinculada a la realidad, al campo de conocimiento disciplinar de aplicación; la investigación está en un contexto cultural, social y político en que se desarrolla y se convierte en la generación de pensamiento libre y útil. La investigación aproxima a científicos de diferentes campos disciplinares, enriquece la formación universitaria y orienta a actores sociales relevantes (Navarro, 2014).

La investigación trata también de temas y materias que no pueden ser cuantificados, es decir, que no pueden ser trasladados a datos numéricos. Los datos, en este sentido, se obtienen a partir de la observación directa, a través de entrevistas, investigación y análisis. De allí que la metodología cualitativa aplique procedimientos interpretativos y analíticos para el abordaje de su objeto de estudio, como tal, es el tipo de metodología más usual en los campos de las ciencias sociales y humanísticas, tiene una perspectiva holística. Esto es que considera el fenómeno como un todo y se trata de estudios en pequeña escala que solo se representan a sí mismos (Palacios, 2014). Se hace énfasis en la validez de las investigaciones a través de la proximidad a la realidad empírica que brinda esta metodología, no suele probar teorías o hipótesis. Es, principalmente, un método de generar teorías e hipótesis no tiene reglas de procedimiento. El método de recogida de datos no se especifica previamente, las variables no quedan definidas operativamente, ni suelen ser susceptibles de medición; la base está en la intuición. La investigación es de naturaleza flexible, evolucionaría y recursiva, en general no permite un análisis estadístico, se pueden incorporar hallazgos que no se habían previsto, los investigadores cualitativos participan en la investigación a través de la interacción con los sujetos que estudian, es el instrumento de medida, analizan y comprenden a los sujetos y fenómenos desde la perspectiva de los dos últimos; debe eliminar o apartar sus prejuicios y creencias (Palacios, 2014).

Se conoce como indicador a aquel dato que refleja cuáles fueron las consecuencias de acciones tomadas en el pasado en el marco de una organización. La idea es que estos indicadores sienten las bases para acciones a tomar en el presente y en el futuro, para que se conozca la eficiencia real que tiene aquella, para que se descubran los puntos débiles y fuertes de la entidad y también para que tener clara la situación de riesgo que posee la misma (Porter \& Kramer, 2006). 


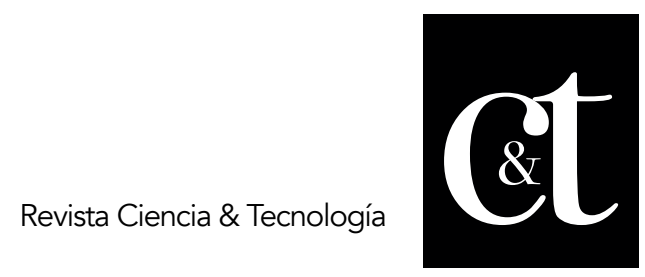

No. 23, 31 de julio de 2019

ISSN impreso: 1390 - 6321

ISSN online: 2661 - 6734

Es importante que los indicadores de gestión reflejen datos veraces y fiables, ya que el análisis de la situación, de otra manera, no será correcto. Estos indicadores:

- Medios, instrumentos o mecanismos para evaluar hasta qué punto o en qué medida se están logrando los objetivos estratégicos.

- Representan una unidad de medida gerencial que permite evaluar el desempeño de una organización frente a sus metas, objetivos y responsabilidades con los grupos de referencia.

- Producen información para analizar el desempeño de cualquier área de la organización y verificar el cumplimiento de los objetivos en términos de resultados.

- Detectan y prevén desviaciones en el logro de los objetivos.

- EL análisis de los indicadores conlleva a generar Alertas sobre la acción, no perder la dirección, bajo el supuesto de que la organización está perfectamente alineada con el plan.

La medición del desempeño puede ser definida generalmente, como una serie de acciones orientadas a medir, evaluar, ajustar y regular las actividades de una empresa. En la literatura existe una infinidad de definiciones al respecto. Su definición no es una tarea fácil dado que este concepto envuelve elementos físicos y lógicos, depende de la visión del cuerpo gerencial, de la composición y estructura jerárquica y de los sistemas de soporte de la empresa (Joanna, 2012).

Los indicadores miden la calidad del producto final o servicio prestado. A diferencia de los cuantitativos, estos indicadores revelan los atributos positivos o valoración de lo realizado, sin limitarse a su simple cantidad (García, 2016).

Los indicadores apuntalados miden cantidades o tiempo. Se calculan con ayuda del cociente entre cantidad de manufacturas y tiempo necesario para su materialización. Igualmente, se utilizan en la relación entre inversión y número de productos consumados (García, 2016).

Indicadores de Proceso: se pretende medir que está sucediendo con las actividades (Pérez, 2014).

Indicadores de resultado: miden la consecuencia del objetivo estratégico. También se les llama indicadores de efecto (Pérez, 2014).

Indicadores de causa: miden el resultado de las acciones que permiten su consecución. También se llaman indicadores inductores (Pérez, 2014).

Indicadores de eficacia: eficaz tiene que ver con hacer efectivo un intento o propósito. Los indicadores de eficacia están relacionados con las razones que indican capacidad o acierto en la consecución de tareas y/o trabajos (Pérez, 2014). 


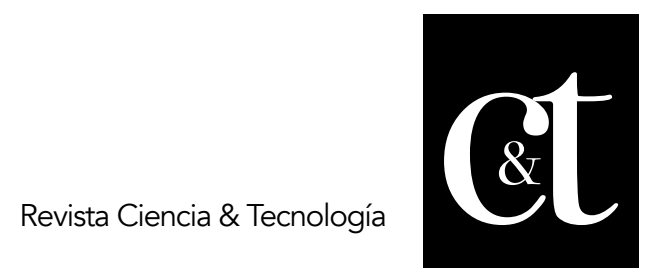

No. 23, 31 de julio de 2019

ISSN impreso: 1390 - 6321

ISSN online: 2661 - 6734

Ejemplo: Grado de satisfacción de los clientes con relación a los pedidos.

Indicadores de eficiencia: teniendo en cuenta que eficiencia tiene que ver con la actitud y la capacidad para llevar a cabo un trabajo o una tarea con el mínimo de recursos. Los indicadores de eficiencia están relacionados con las razones que indican los recursos invertidos en la consecución de tareas y/o trabajos (Pérez, 2014).

Ejemplo: Tiempo fabricación de un producto, razón de piezas / hora, rotación de inventarios.

Indicadores de cumplimiento: con base en que el cumplimiento tiene que ver con la conclusión de una tarea. Los indicadores de cumplimiento están relacionados con las razones que indican el grado de consecución de tareas y/o trabajos (Pérez, 2014).

Ejemplo: cumplimiento del programa de pedidos.

Indicadores de evaluación: la evaluación tiene que ver con el rendimiento que se obtiene de una tarea, trabajo o proceso. Los indicadores de evaluación están relacionados con las razones y/o los métodos que ayudan a identificar nuestras fortalezas, debilidades y oportunidades de mejora (Pérez, 2014).

Ejemplo: evaluación del proceso de gestión de pedidos.

Indicadores de gestión: teniendo en cuenta que gestión tiene que ver con administrar y/o establecer acciones concretas para hacer realidad las tareas y/o trabajos programados y planificados. Los indicadores de gestión están relacionados con las razones que permiten administrar realmente un proceso (Pérez, 2014).

Ejemplo: administración y/o gestión de los almacenes de productos en proceso de fabricación y de los cuellos de botella.

La recuperación de información bibliográfica constituye la etapa fundamental de todo proyecto de investigación. Esta debe garantizar la obtención de la información más relevante en el campo de estudio, de una fuente de documentos científicos muy extenso dado que en la actualidad se dispone de mucha información y su crecimiento es exponencial, manejándola de forma eficiente, la revisión bibliográfica corresponde a la descripción detallada de cierto tema o tecnología, pero no incluye la identificación de tendencias que puedan plantear diferentes escenarios sobre el desarrollo del tema en cuestión y que permitan tomar decisiones estratégicas. Este tipo de metodología que se presenta para la revisión bibliográfica está compuesto de tres fases fundamentales, las cuales deben retroalimentarse a lo largo de la búsqueda (Guerrero \& Guerrero, 2014). 


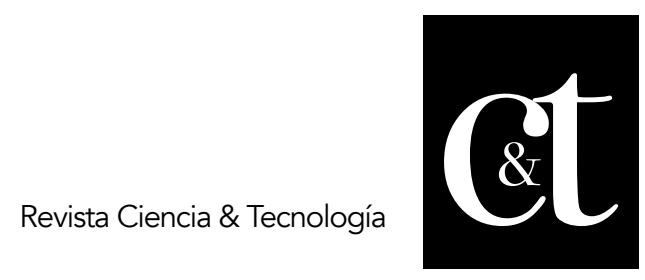

No. 23, 31 de julio de 2019

ISSN impreso: 1390 - 6321

ISSN online: 2661 - 6734

Con el uso de las nuevas tecnologías y herramientas digitales presente en las plataformas en forma de software se puede realizar estructuración de la información y en ciertos casos. Algunas son tan avanzadas que hacen minería de datos y estadística multivariada para facilitar la obtención de información que no se tendría a simple vista (Matesanz, Garralon, Jordan, \& Diaz, 2017).

\section{Tabla 3. Software de apoyo para la gestión documental}

Nombre

\section{Característica}

un software analizador que lee los contenidos de Internet, de base de datos locales, de bases de artículos científicos y de patentes.

\section{GOLDFIRE \\ Apoyo a la \\ VT y gestión documental}

una herramienta de software diseñada para recuperar información de fuentes no estructuradas, semi-estructuradas, estructuradas.
Identifica las soluciones a preguntar hechas en lenguaje natural, permite la extracción de valor de los documentos. Permite establecer la evolución de una tecnología, el perfil de una organización en cuanto a su actividad de patentes; identificar las organizaciones implicadas en el desarrollo de determinadas patentes, la citación de patentes, de inventos, entre otras

$\begin{array}{llr}\text { WebQL } & \text { una } & \text { herramienta de } \\ & \text { software diseñada } & \text { para } \\ & \text { recuperar información de } & \text { de } \\ & \text { fuentes no estructuradas, } \\ & \text { semi-estructuradas, } & \text { y } \\ & \text { estructuradas. } & \end{array}$
La información es extraída en diferentes formatos: HRML, XML, pdf, doc, CSV, TSV, imágenes, bases de datos, entre otros. También permite navegar a través de sitios pertenecientes a la "Deep web".

Permite la búsqueda automática de patentes, y si gestión documental. 


$\begin{array}{ll} & \text { Es un software para la gestión } \\ & \text { documental de la } \\ \text { investigación. Se basa en la } \\ \text { organización categórica de los } \\ \text { documentos y referencias en } \\ \text { Zotero } & \text { múltiples formatos. }\end{array}$

Mendeley

Desktop

JabRef

Es un gestor documental de código abierto desarrollado sobre Java.
La ventaja de Zotero está en su integración con los navegadores de Internet, la posibilidad de sincronización y el uso de diferentes formatos.

Las ventajas están en su utilización intuitiva, el manejo de documentos, la facilidad de importación y exportación y el compartimiento de documentos en grupos privados $y$ públicos, dando soporte al trabajo de investigación en la red social Científica.

Es una multiplataforma de código abierto, que opera bajo el formato BibtEXT, lo cual permite la personalidad y adaptabilidad a las distintas fuentes de información. Permite crear etiquetas automáticas por títulos, autores y otros campos Adicionales.

Fuente: DYNA

Elaborado por: Elaboración propia

\section{Metodología}

La metodología bibliográfica es aplicable a cualquier tema de investigación para determinar la relevancia e importancia del mismo y su originalidad de una investigación; además, permite que otros investigadores consulten las fuentes bibliográficas citadas, pudiendo entender y quizá continuar el trabajo realizado (Guerrero \& Guerreo, 2014).

En esta primera fase se debe ser claro y conciso para poder realizar una búsqueda bibliográfica que responda a las necesidades del investigador y que además aporte al estado de la técnica, de manera que conduzca a un escenario bastante amplio y permita la retroalimentación de la investigación (Muñoz, 2016). 


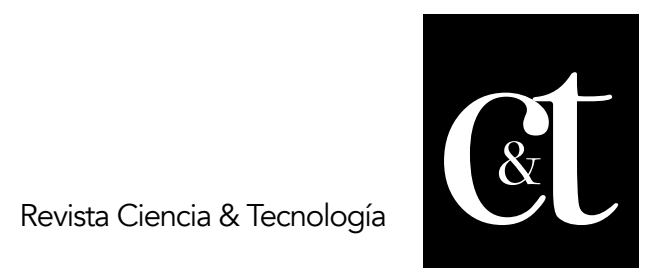

No. 23, 31 de julio de 2019

ISSN impreso: 1390 - 6321

ISSN online: 2661 - 6734

Se debe contar con material informativo como libros, revistas de divulgación o de investigación científica, sitios Web y demás información necesaria para iniciar la búsqueda. Una búsqueda bibliográfica debe hacerse desde una perspectiva estructurada y profesional, leer documentación científica con fundamentos es entretenido, educativo y aprovecha el tiempo que se le ha invertido (Miguel, 2017). Al iniciar una búsqueda bibliográfica no se sabe qué material es el más pertinente 0 relevante, sin embargo, a medida que se avanza la perspectiva mejora y se empiezan a definir los temas que realmente interesan; por tanto, se delimita la búsqueda. Los trabajos reconocidos son aquellos que han sido revisados cuidadosamente por profesionales expertos antes de su población, dentro de un formato establecido reconocidos y mejor valorados académicamente que otros, entre estos: libros, revistas, actas de congresos, reportes técnicos, normas, tesis e Internet (Muñoz, 2016).

Esta fase es de gran importancia en toda investigación y consiste en organizar de manera sistemática la documentación encontrada. Se puede realizar tanto de manera básica o detallada. Inicialmente la información puede ser ordenada en carpetas, hojas de cálculo, archivos, documentación digital, blogs, entre otros por el propio investigador de forma manual, sin embargo, el proceso es lento y deficiente; otra manera de hacerlo es mediante el uso de programas especiales tales como: JabRef, Zotero, Mendele, Endnote y Reference manager (Matesanz, Garralon, Jordan, \& Diaz, 2017).

La tercera fase es analizar la información ya organizada. Se infiere sobre cuáles son los documentos más útiles para la temática en estudio. El análisis de la información es la tarea que toma más tiempo en la investigación bibliográfica, ya que con ella se espera identificar el aporte a realizar. En esta fase se debe tener un pensamiento crítico, dado que es un proceso constante donde se reafirman las ideas planteadas en la formulación del problema y si se conoce bien el problema, se genera la solución en base al información estudiada (Matesanz, Garralon, Jordan, \& Diaz, 2017).

\section{Resultados}

En el presente artículo se analiza mediante un estudio de tipo referencial bibliográfica la información recuperada de literatura especializada aplicando un análisis de las fuentes primarias INEC, tesis, páginas web del gobierno, Banco Central y artículo especializado en el tema; como libros revistas, tesis, páginas web y las fuentes secundarias que son resúmenes de bases de datos confiables y especializadas, y una tercera fuente de información la cual nos ayuda a discriminar de la base de datos lo que no aportará a la investigación.

La revisión de la literatura sigue una secuencia ordenada y metodológica, el marco teórico aporta para realizar una investigación científica; así se garantiza que el trabajo sea de impacto en la ciencia. 


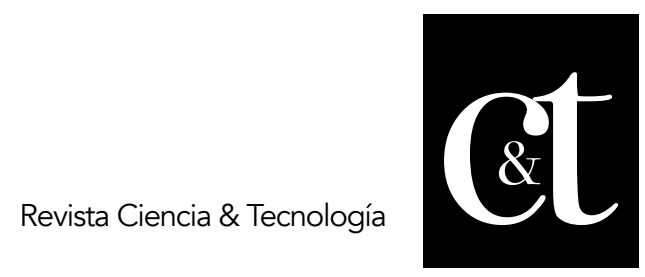

No. 23, 31 de julio de 2019

ISSN impreso: 1390 - 6321

ISSN online: 2661 - 6734

La población objetivo en el presente trabajo de investigación bibliográfica corresponde a la población económicamente activa de la provincia de Tungurahua de 294.796 personas, teniendo como eje central al PEA del sector agrícola, ganadería, silvicultura y pesca que está formada por un total de 74.486 personas, sexo masculino y femenino, en edad comprendida entre 18 y 35 años con un nivel educativo de secundaria y universitario y clasificadas las empresas de acuerdo al sector privado y público en el año 2017. Esta población fue elegida porque desarrollan actividades empresariales y los factores de calidad de vida pueden ser analizadas en este grupo que poseen las mismas variables de comportamiento, tasa de empleo, desempleo, tasa de pobreza en las principales zonas productivas (hogares pobres, hogares con pobreza extrema), tasa de analfabetismo, PIB agrícola (2015 y 2016), superficie sembrada y producción (2017).

En base a la problemática en el estudio, acerca de la cadena de producción se delimita dada la limitada información sobre el manejo de campo, pos-cosecha y comercialización por lo que genera irregularidad en los datos referenciales actualizados. No hay una secuencia en la producción regular, por lo cual existe disparidad productiva entre cada año, uso de sistemas tradicionales pocos productivos comparados con las tecnificaciones actuales implantadas en otros países, la poca generación de tecnología y asesoramiento técnico que reciben los productores afecta directamente al producto final que afecta la cantidad, calidad y continuidad de comercialización que encare la producción y disminuye los beneficios.

La investigación se basa en documentación e información de tipo bibliográfica mediante el estudio y análisis de aspectos relevantes de información con validez de carácter científico. La amplitud bibliográfica será el referente indispensable para denotar y sustentar la investigación con la fincalidad de formular nuevas investigaciones en relación al tema propuesta.

Se analizan temas como: tasa de empleo, desempleo, pobreza en las principales zonas productivas (hogares pobres, hogares con pobreza extrema), tasa de analfabetismo, PIB agrícola (2015 y 2016), superficie sembrada y producción (2017).

Todos estos datos obtenidos de ministerios provinciales y del Banco Central del Ecuador, son de carácter bibliográfico- descriptivos y se aplicó el método de lectura analítica comparativa entre las diferentes fuentes.

La organización de la documentación se cuenta como información tomando en cuenta la fuente, el año de impresión, etc. 


\section{Tabla 4. PIB del Ecuador}

\begin{tabular}{lll} 
Sector Real & & \\
PRODUCTO INTERNO BRUTO (+) & 2015 & 2016 \\
\hline Tasa de variación anual (USD 2007) & $0,2 \%$ & $-1,5 \%$ \\
\hline PIB (millones USD 2007) & 70.354 & 69.321 \\
\hline PIB per capital (USD 2007) & 4.322 & 4.194 \\
PIB (millones USD corrientes) & 100.177 & 97.802 \\
Pib per cápita (USD corrientes) & 6.154 & 5.917 \\
TASA DE VARIACIÓN PIB TRIMESTRAL & $2016.11 \mathrm{I}$ & $2016 . \mathrm{IV}$ \\
(CVE) & & \\
PIB TOTAL, a precios constantes, Base $\mathbf{2 0 0 7}$ & $0,7 \%$ & $1,7 \%$ \\
(++) & &
\end{tabular}

Superficie sembrada y producción de la Uvilla 2017

\begin{tabular}{|c|c|c|c|c|c|c|}
\hline \multirow[t]{3}{*}{$\begin{array}{l}\text { PROVINCI } \\
\text { AS }\end{array}$} & SUPERFICIE & RENDIMIENTO & $\begin{array}{l}\text { PRODUCCIÓN } \\
\text { (TM) }\end{array}$ & PEA & PEI & KILOMETROS \\
\hline & $\begin{array}{l}\text { SEMBRA } \\
\text { DA }\end{array}$ & $(\mathrm{TM} / \mathrm{HA})$ & & & & $\begin{array}{l}\text { CUADRAD } \\
\text { OS }\left(\mathrm{KM}^{\complement}\right)\end{array}$ \\
\hline & (HAS) & & & & & \\
\hline CARCHI & 20,00 & 50,00 & 1000,00 & $\begin{array}{c}65,0 \\
\%\end{array}$ & $\begin{array}{c}35,0 \\
\%\end{array}$ & 3780,45 \\
\hline IMBABURA & 60,00 & 50,00 & 3000,00 & $\begin{array}{c}65,5 \\
\%\end{array}$ & $\begin{array}{c}34,5 \\
\%\end{array}$ & 4587.51 \\
\hline PICHINCH A & 100,00 & 50,00 & 5000,00 & $\begin{array}{c}64,4 \\
\%\end{array}$ & $\begin{array}{c}35,6 \\
\%\end{array}$ & 9535.91 \\
\hline COTOPAXI & 15,00 & 50,00 & 750,00 & $\begin{array}{c}74,9 \\
\%\end{array}$ & $\begin{array}{c}25,1 \\
\%\end{array}$ & 6108.23 \\
\hline $\begin{array}{l}\text { TUNGURA } \\
\text { HUA }\end{array}$ & 5,00 & 60,00 & 300,00 & $\begin{array}{c}74,5 \\
\%\end{array}$ & $\begin{array}{c}25,5 \\
\%\end{array}$ & 3386,25 \\
\hline TOTAL & 200,00 & $\begin{array}{l}52,00 \\
\text { (Promedio) }\end{array}$ & $10.050,00$ & & & \\
\hline
\end{tabular}

Fuente: INEC, 2017

Elaborado por: Elaboración propia. 
Tabla 5. Estudio de producción de la uvilla

\begin{tabular}{lll}
$\begin{array}{l}\text { Agricultura, ganadería, caza, silvicultura y } \\
\text { pesca }\end{array}$ & $-0,1 \%$ & $0,6 \%$ \\
\hline $\begin{array}{l}\text { Explotación de minas y canteras } \\
\begin{array}{l}\text { Industria manufacturera (incluye refinación } \\
\text { de petróleo) }\end{array}\end{array}$ & $0,1 \%$ & $-0,4 \%$ \\
\hline $\begin{array}{l}\text { Construcción } \\
\text { Comercio al por mayor y menor }\end{array}$ & $3,1 \%$ \\
\hline $\begin{array}{l}\text { Administración pública } \\
\text { Resto de Servicios (+++) }\end{array}$ & $-2,2 \%$ & $0,2 \%$ \\
\hline
\end{tabular}

Fuente: Estudio de la cadena productiva de la uvilla.

Elaborado por: Elaboración propia.

Tabla 6. Comparación de la pobreza por provincias

\section{Provincias Población según nivel de pobreza}

$\begin{array}{ll}\begin{array}{l}\text { Población no } \\ \text { pobre }\end{array} & \begin{array}{l}\text { Población Total } \\ \text { pobre }\end{array}\end{array}$

$\begin{array}{llrr}\text { Carchi } & 69,728 & 93,049 & 162,777 \\ \text { Imbabura } & 394,735 & 428,482 & 823,217 \\ \text { Pichincha } & 1,702,46 & 855,983 & 2,558,450 \\ & 7 & & \\ \text { Cotopaxi } & 101,152 & 304,474 & 405,626 \\ \mathbf{2 1 5 , 2 6 2} & 215,262 & 285,524 & 500,786\end{array}$

$\begin{aligned} & \text { Población según nivel } \\ & \text { de pobreza }\end{aligned}$
$\begin{array}{cl}\% \text { Población } & \% \\ \text { no pobre } & \begin{array}{l}\text { Población } \\ \text { pobre }\end{array}\end{array}$

\begin{tabular}{cc}
$42,8 \%$ & $57,2 \%$ \\
$45,8 \%$ & $54,2 \%$ \\
$66.50 \%$ & $33.50 \%$ \\
& \\
\hline $24.90 \%$ & $75.10 \%$ \\
$43.00 \%$ & $57.00 \%$
\end{tabular}

Fuente: INEC 2017.

Elaborado por: Elaboración propia.

Los 142 documentos encontrados fueron organizados y analizados, aplicando los criterios de selectividad para identificar los más relevantes; para lo cual se agrupó por temáticas, origen y años de publicación. Esto permite ver todo el universo de búsqueda clasificado en temáticas, facilitando el poder consultarlos y comprarlos entre sí.

La bibliografía recuperada inicialmente fue agrupada por temas de interés relacionados y categorías, facilitando el análisis de la información en las etapas posteriores, permitiendo la diferenciación de documentos principales de los 


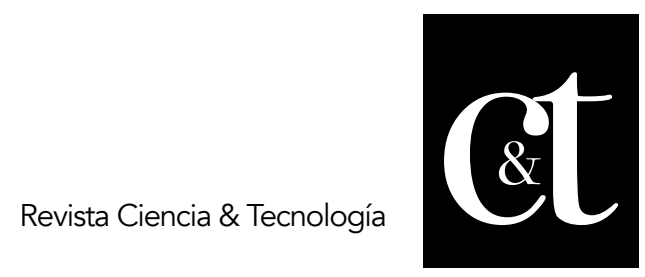

No. 23, 31 de julio de 2019

ISSN impreso: 1390 - 6321

ISSN online: 2661 - 6734

secundarios (datos), tomando encuneta los autores que más han publicado en la temática de estudio, los que más han sido citados y la relación de las publicaciones con los años.

Teniendo como punto de partida la superficie de siembra, las principales zonas productoras de uvilla en la sierra norte, se tiene que Carchi cuenta con $20 \mathrm{Ha}$., con un rendimiento de $50 \mathrm{Tm}$ dando una producción de $1000 \mathrm{Tm}$; Imbabura $60 \mathrm{Ha}$., con rendimiento de $50 \mathrm{Tm}$ dando una producción de $3.000 \mathrm{Tm}$; Pichincha $1000 \mathrm{Ha}$., que genera un rendimiento de $50 \mathrm{Tm}$ dando una producción de $5000 \mathrm{Tm}$; Cotopaxi $15 \mathrm{Ha}$ que genera un rendimiento de $50 \mathrm{Tm}$ dando una producción de $750 \mathrm{Tm}$; y por ultimo Tungurahua con un área de $5 \mathrm{Ha}$., con un rendimiento de $60 \mathrm{Tm}$. y da una producción de $300 \mathrm{Tm}$. Todas estas cifras están en función a producción anual.

Con fundamento en los datos recabados acerca de la Población económicamente activa (PEA) y Población Económicamente Inactiva (PEI) de las principales zonas de producción de uvilla en la sierra norte se puede constatar que Carchi tiene un PEA del $65 \%$ y una PEI $35 \%$; para Imbabura, su respectiva PEA está en $65,5 \%$ con PEI del 34,5\%; Pichincha muestra un PEA del $64,4 \%$ y su PEI con $35,6 \%$; en Cotopaxi, el PEA se ubica en $74,9 \%$, en contraste con un PEI del $25,1 \%$; y para la provincia de Tungurahua, se presentaba un PEA del $74,5 \%$, con un índice de PEI del 25,5\%.

En contraste, se determina que la población que compone a cada una de estas provincias presenta los siguientes índices: Carchi $42,8 \%$ población no pobre y el $57,2 \%$ población pobre; Imbabura $45,8 \% \%$ población no pobre y el $54,2 \%$ población pobre; Pichincha $66,5 \%$ población no pobre y el 33,5\% población pobre; Cotopaxi $24,9 \%$ población no pobre y el $75,1 \%$ población pobre y finamente Tungurahua con un $60,4 \%$ de población no pobre y el $39,6 \%$ población pobre.

Tungurahua presenta una tasa de analfabetismo distribuido de un universo total de 410.994 niños de entre 10 años a casi lo 15 existe 23.664 que no sabe leer ni escribir; de un total de 361.800 de chicos de 15 años hasta los 18 se presenta 24.358 individuos que no saben leer o escribir.

Al abordar la problemática de la cadena y en la definición del plan de acción, los Gobiernos Autónomos Descentralizados (GAD) de Tungurahua para el pedido de 2015 al 2019, trazaron el siguiente curso de acciones para mejorar la situación presente, a mediano y largo plazo. Estas estrategias buscan el minimizar los factores que afectan a la cadena de producción no solo al sector frutícola; de igual forma en otros ejes estratégicos productivos vitales. Se definieron acciones de asistencia técnica, capacitaciones, acceso a mercados y mecanismos para superar las restricciones técnicas y financieras.

Otras acciones incluyeron: aplicación de acciones afirmativas en el sistema de productividad y de comercialización provincial, fortalecer el acceso de las mujeres al sector productivo para potenciar su autonomía económica, fortalecer redes que trabajan en la prevención y sensibilización contra la violencia de género generación, generación de información permanente y adecuada por parte de las instituciones involucradas en la 


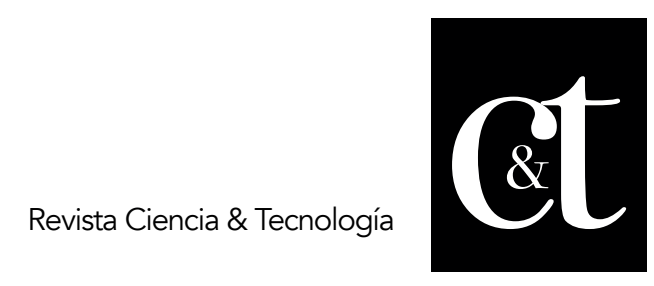

No. 23, 31 de julio de 2019

ISSN impreso: 1390 - 6321

ISSN online: 2661 - 6734

ruta de atención integral para víctimas de violencia de género, implementar la ruta con carácter de aplicación obligatoria, elevada a política pública a través de los consejos de protección de derechos y las comisiones de igualdad de género de los de la GAD municipales, con el apoyo del sistema de protección de Derechos Humanos, participar y proponer políticas para mujeres, sus programas y respectivos financiamientos y Plan de sensibilización y prevención de violencia de género.

Entre otras acciones se procedió a generar una campaña de capacitación masiva para conocer y aprovechar las oportunidades que se generan con el convenio de comercialización con la Unión Europea; diseño de un sistema de comercialización local, regional y nacional (acopio y venta); incentivo a la apicultura y sistema de producción y bondades de los productos apícolas; implementación de la normativa para el cambio de envases en el Mercado Mayorista; gestionar financiamiento para la implementación del Centro Comercial y Transferencias Municipio de Ambato y Unamuncho; fortalecer el Centro de Comercialización Municipio Tisaleo de mora y fresa; implementar los Centros de Comercialización de los Municipios de Cevallos Patate, Píllaro y Mocha y aplicar la Marca Productiva Tungurahua, para posicionar nuestra producción en el país.

Articulación de los mecanismos y estrategias para la implementación de los programas de manejo de parámetros con un enfoque de parroquia, cantón y provincia: formulación de los Planes de Desarrollo Económico Local en los 44 gobiernos parroquiales, alineados a las agendas productivas cantonales y provinciales.

Implementación del Centro de Fomento Productivo multifocal para las cadenas productivas de: textiles $\&$ confecciones, Cuero $\&$ calzado y turismo en las aduanas.

Temáticas disponibles: La asociatividad y el emprendimiento, procedimiento parlamentario en el marco de la EPS y atención al cliente.

Temáticas disponibles: desarrollo humano, liderazgo integrador; deberes y derechos de los jóvenes; derechos sexuales y de la reproductivos; participación ciudadana y el nuevo Modelo de Gestión de Tungurahua, Comunicación y Emprendimiento.

Temáticas disponibles: desarrollo humano; derechos de los adultos mayores; liderazgo y fortalecimiento organizativo; salud preventiva en personas adultas y participación ciudadana y el Nuevo Modelo de Gestión de Tungurahua.

Temáticas disponibles: desarrollo humano; enfoque de género y enfoque de equidad; roles de género; los derechos y las mujeres; la propuesta de la equidad; participación ciudadana y Nuevo Modelo de Gestión de Tungurahua, Comunicación asertiva y Justicia indígena.

Temáticas disponibles: derecho y salud para las mujeres; prevención de la morbimortalidad materno infantil rural; saberes que curan; acompañamiento familiar y parteras en la salud de las madres en el sector rural y parteras y el sistema de salud pública. 


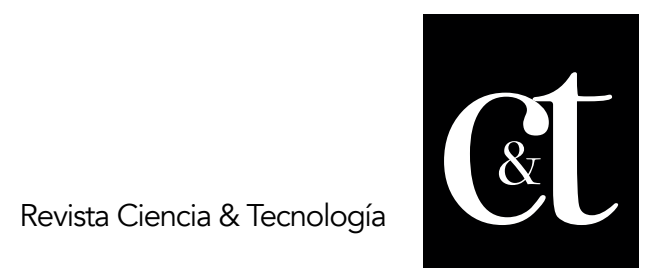

No. 23, 31 de julio de 2019

ISSN impreso: 1390 - 6321

ISSN online: 2661 - 6734

Temáticas disponibles: liderazgo y el y gobernabilidad; participación ciudadana y el Nuevo Modelo de Gestión de Tungurahua; ética y cultura de cambio barrial; trabajo en equipo y bien común (el valor de la minga); procedimiento parlamentario; resolución de conflictos; manejo de residuos sólidos y buenas prácticas ambientales en los barrios y comunidades.

El nuevo Modelo de Gestión de la Provincia de Tungurahua, nace en un escenario en que las instituciones políticas y organizaciones sociales trabajan de manera independiente y desarticulada. Trece años atrás se reúnen los actores de la sociedad civil junto a las autoridades electas a decidir en la mesa de diálogo sobre las sobre cuáles deberían ser los objetivos provinciales; así, cobijando se bajó el lema "Todos somos Gobierno" y se instala la primera Asamblea Provincial en el año 2003 y nace el Nuevo Modelo de Gestión de la provincia de Tungurahua, con espacios parlamentarios de debate y formulación de propuestas en los tres ejes estratégicos: Agua, Gente y Trabajo. Junto a un grupo de interés se impulsan propuestas ciudadanas bajo los objetivos comunes y se define el sistema de participación bajo los principales de representatividad, gobernabilidad y corresponsabilidad.

A la luz de este escenario de trabajo bajo objetivos y acuerdos comunes, se empezó definiendo políticas de fomento productivo, generadas de manera participativa en el sector público, privado y la académica, a través de cuatro estrategias que se han convertido en la bitácora de navegación del sector productivo: La Estrategia Agropecuaria, La Agenda de Turismo, La Agenda de Competitiva y La Agenda Artesanal misma que se orienta a la inversión del sector público y a la corresponsabilidad de los sectores privados en los logros de objetivos comunes.

Se hace hincapié en el trabajo cooperativo entre las instituciones públicas que aportan en la formulación de estás agendas, balanceando las propuestas de los encadenamientos y atándolas a las políticas sectoriales de Gobierno Nacional y el Plan Nacional del Buen Vivir, integrando un equipo técnico de alto nivel que planificó y desarrollo las actividades para el levantamiento participativo de la agenda unificada bajo los siguientes enfoques:

\section{Conclusiones}

En base a la recuperación de datos bibliográficos obtenida de fuentes primarias y secundarias se identificó los siguientes factores: las principales provincia de productora, superficie de sembrada, rendimiento, producción, población económicamente activa, población económicamente inactiva, población pobre, población no pobre, tasa de empleo, distribución de hogares según la ubicación rural o urbana y la tasa de analfabetismo, como factores que inciden directamente en el rendimiento del sector productivo.

A lo largo de la presente investigación se denotó la falta de información sobre el tema de los productores de uvillas en las diferentes provincias analizadas, de igual forma la existente es poco detalla como actualizada dificultado la recolección de datos 


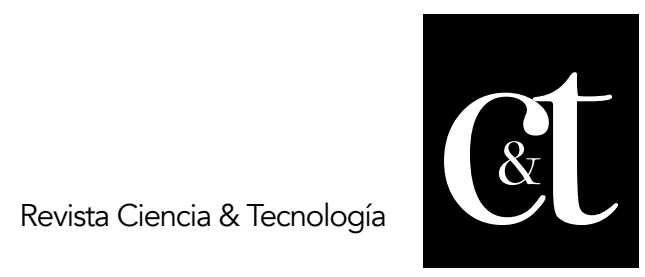

No. 23, 31 de julio de 2019

ISSN impreso: 1390 - 6321

ISSN online: 2661 - 6734

necesarios.

El estudio sobre la cadena de producción y los factores que inciden en sus resultados ha sido abordado por pocos autores, en la recolección de información se encontraron una gran cantidad de estudios aplicados en países de la zona andina relacionados la producción de uvilla. Con esta revisión se logró identificar las características relevantes para la selección de la estructura en la cadena producción de la uvilla.

\section{Referencias bibliográficas}

Alles, M. (2015). 5 pasos para transformar una oficina de personal en un área de Recursos Humanos. Buenos Aires: GRANICA.

Altamirano, M. (2010). Estudio de la cadena productiva de la uvilla (Physalis peruviana) en la Sierra Norte del Ecuador. Quito, Pichincha, Ecuador: Universidad San Francisco de Quito. Obtenido de http://repositorio.usfq.edu.ec/bitstream/23000/950/1/95220.pdf

Añez, C. (noviembre de 2015). Flexibilidad laboral: ¿fin del trabajo. Dialnet. Obtenido de file:///C:/Users/VIKTOR/Downloads/Dialnet-FlexibilidadLaboral$5655392 \% 20(1) . p d f$

Campuzano, M., Ziadet, E., \& Echeverria, H. (7 de Julio de 2016). Gestión del Talento Humano en las PYMES. Revista Publicando. Obtenido de file:///C:/Users/VIKTOR/Downloads/272-1103-1-PB.pdf

Coronel, P. (2016). "Plan de negocios para la creación de una empresa dedicada a la fabricación y comercialización de mermeladas hechas a base de uvilla en la ciudad de quito". Quito, Pichincha, Ecuador: UDLA. Obtenido de http://dspace.udla.edu.ec/bitstream/33000/4878/1/UDLA-EC-TINI-2016-43.pdf

Coutintho, C. P. (2014). Metodología de investigación en ciencia sociales humanas: teoría y práctica. Coímbra, Portugal: Grupo Almeida.

Obtenido

https://books.google.com.ec/books?hl=en\&lr=\&id=uFmaAwAAQBAJ\&oi=fnd $\& p g=$ PT3\&dq $=$ metodologia + de+investigacion\&ots $=$ GgcIYDi_T7\&sig $=$ wclpgd vjjMw2ukmAHED5bdQAHKo\&redir_esc=y\#v=onepage\&q=metodologia\%20d e\%20investigacion \&f $=$ false

Gálvez, G. E. (6 de septiembre de 2006). Gestiopolis. Obtenido de: https://www.gestiopolis.com/la-cadena-productiva-y-los-sistemas-de- producción/ 


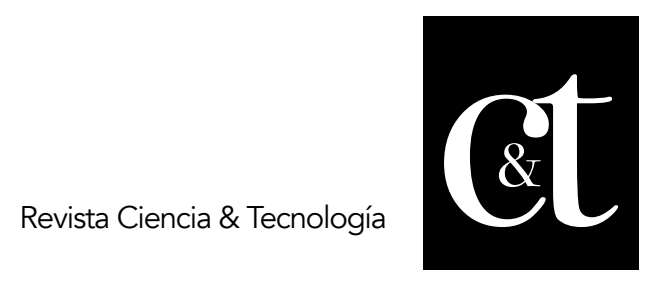

No. 23, 31 de julio de 2019

ISSN impreso: 1390 - 6321

ISSN online: 2661 - 6734

García, L. A. (2016). Indicadores de la gestión logística. Bogotá, Colombia: Ecoe. https://books.google.com.ec/books?hl=en\&lr=\&id=ItzDDQAAQBAJ\&oi=fnd\& $\mathrm{pg}=\mathrm{PT}$ \& dq $=$ que + son + indicadores\&ots $=$ pozoa -

B341\&sig $=j$ XAJ3tKKrvEVKxO8InwLRezJPsg\&redir_esc $=y \# v=$ onepage\& $q=q u$ e\%20son\%20indicadores\&f=false

Gasparini, L., \& Marchionni, M. (Junio de 2015). La Participación Laboral Femenina en América Latina: Avances, Retrocesos y Desafíos. SEDECI. Obtenido de http://sedici.unlp.edu.ar/bitstream/handle/10915/51287/Versi\%C3\%B3n_en__cast ellano.pdf?sequence $=1$

Gelabert, M. P. (2014). Gestión de personas. (6º, Ed.) Madrid, España: Business \& marketing school. Obtenido de:

https://books.google.com.ec/books?hl=en\&lr=\&id=30RxBAAAQBAJ\&oi=fnd $\& p g=P A 19 \& d q=$ capital + humano $+y+$ cadena + productiva\&ots $=30$ CjIQL5kI\&sig $=$ p37HeCicVNdapBNOgQ0yf5028CE\&redir_esc=y\#v=onepage\&q=capital $\% 20$ humano\%20y\%20cadena\%20productiva\&f=false

González-Corzo, M. (2015). La agro industria cañera cubana: transformaciones recientes. (R. Lopez, Ed.) New York: Estados Unidos.

Gottret, M., \& Lundy, M. (2007). Gestión de cadenas productivas. Cali, Colombia: CIAT. Obtenido de https://books.google.com.ec/books?id=PN3ufBC$3 z Y C \& p g=P A 28 \& d q=$ enfoque + tradicional ++ cadena + productiva ++ pdf\&hl $=e s$ $\mathrm{sa}=X \& v e d=0 a h U K E w i a 2 \_v j 7 I j c A h W P r V k K H T c 6 C m g Q 6 A E I J j A A * v=$ onepage

Guamán, M., Caisa, E., Acosta, M., Miranda, R., \& Fidel, C. (2017). Mercado Corporativo Interno. Ambato, Ecuador: Universidad Técnica de Ambato.

Guerrero, G., \& Guerrero, C. (2014). Metodología de la Investigación. México D.F.: México. Ed. Patria.

Obtenido de: https://books.google.com.ec/books?id=DaGEBgAAQBAJ\&pg=PR6\&dq

=metodología + ede + investigación + bibliografía\&hl=es\&sa $=X \& v e d=$ )ahUKWwjgyuL

O_orcAhWIr1kKHTIRDykQ6AEIKDAA\#v=onepage\&q=metodología\%20ede\%20inve stigacion $\% 20$ bibliografia\& $=$ false

Gutiérrez, A. J. (2013). La gestión del talento y la generación de valor de la empresa.

Repositorio Académico UPC, 21.2 Obtenido de https://repositorioacademico.upc.edu.pe/bitstream/handle/10757/333455/5 1 161- 1-PB.pdf?sequence $=1$ \&isAllowed $=y$

INIAP (2016). Cadenas agroproductivas en el Ecuador. Quito: Ecuador. INIAP. 


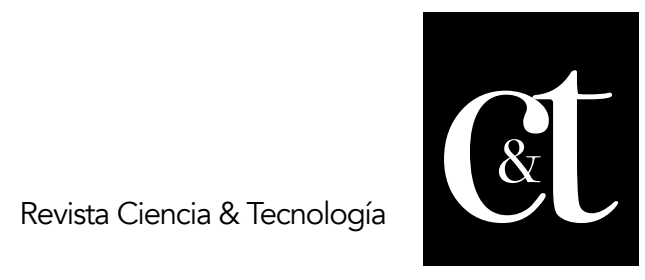

No. 23, 31 de julio de 2019

ISSN impreso: 1390 - 6321

ISSN online: 2661 - 6734

Intermedias, S. A. (2014). Proyecto de desarrollo de cadenas. MICIP. Quito: Ecuador. Obtenido de https://www.industrias.gob.ec/wpcontent/uploads/2018/05/SENPLADES-Proyecto-de-Desarrollo-de-CadenasProductivas-ENCADENA-Ecuador.pdf

Joanna, C. (28 de noviembre de 2012). Gestiopolis. Obtenido de https://www.gestiopolis.com/indicadores-de-gestion-que-son-y-por-que-usarlos/

Jumbo, B. (18 de 2 de 2018). El ejemplo de Ambato y Tungurahua. El Comercio. Obtenido de http://www.elcomercio.com/opinion/ejemplo-ambato-tungurahuaopinion-produccion.html\#

Mejía, A., Bravo, M., \& Montoya, A. (2013). El factor del talento humano en las organizaciones. Scielo. V. 34(1); pp. 2-11.

Miguel, J. M. (2017). Metodológicos Cuadernos. Madrid, España: CIS. Obtenido de https://books.google.com.ec/books?hl=en\&lr=\&id=rxxHDWAAQBAJ\&oi=fnd\& $\mathrm{pg}=\mathrm{PA}$ 9 \&q $=$ metodologia + de+investigacion\&ots $=$ sBKN3mpely\&sig $=$ Im7F2I A qrCcUEZXHgaiOmHvLTI\&redir_esc $=y \# v=$ onepage \&q\&f=false

Muñoz, C. (2016). Metodología de la investigación. México D.F., México: OXFORD. Obtenido de:

ttps://books.google.com.ec/books?id=DflcDwAAQBAJ\&pg=PT526\&dq=metodologia +ede+investigacion+bibliografia\&hl=es\&sa=X\&ved=0ahUKEwjgyuLO_orcAhWIr1k KHTIRDykQ6AEINDAC\# $\mathrm{v}=$ onepage\& $\mathrm{q}=$ metodologia\%20ede\%20investigacion $\% 20 \mathrm{~b}$ ibliografia\& $\mathrm{f}=$ false

Navarro, C. (2014). Epistemología y metodología. México D.F. Grupo Editorial Patria. Obtenido de:

https://books.google.com.ec/books?id=RtrhBAAAQBAJ\&pg=PA254\&dq=carac

teristicas $+\mathrm{de}+\mathrm{la}+$ metodologia + de+investigacion\&hl=es\&sa $=\mathrm{X} \& v e d=0 \mathrm{ahUKEwi} 1 \mathrm{sP}$ bs2YrcAhUN7IMKHeSHDv8Q6AEIMDAB\#v=onepage\&q=características\%20de\%20I a\%20metodologia\%20de\%20investigacion\&f=false

Olivos, P. C., Orue, F., Martínez, J. L., Moreno, Y. M., \& Nava, G. L. (Enero de 2015).

Modelo de gestión logística para pequeñas. Contaduría y Administración 60. 


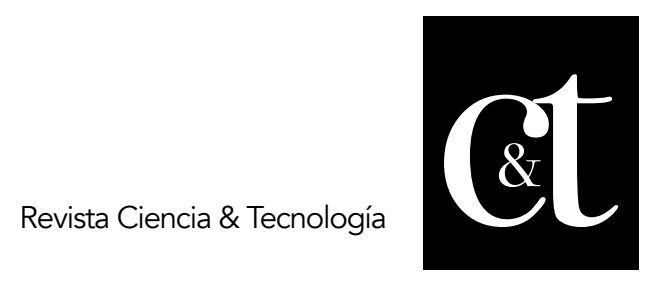

No. 23, 31 de julio de 2019

ISSN impreso: 1390 - 6321

ISSN online: 2661 - 6734

Palacios, S. P. (2014). Manual de Investigación Cualitativa. México D.F., México: Fontamara.

Paz, G. B. (2014). Metodología de Investigación. DF México, México: Grupo Editorial Obtenido https://books.google.com.ec/books?hl=en\&lr=\&id=6aCEBgAAQBAJ\&oi=fnd\& de: $\mathrm{pg}=\mathrm{PP} 1 \& \mathrm{dq}=$ metodologia + de + investigacion\&ots $=$ NU19wQMp0y\&sig $=-$ oEM4XhlzBaVcw2NJxI4RL56mVI\&redir_esc $=y \# v=$ onepage\&q\&f=false

Peiró, R. (2015). Obtenido de: http://economipedia.com/definiciones/cadena-de-valor.html

Pérez, R. P. (2014). Fortalecimiento de las cadenas de valor como instrumento de la política industrial. Santiago de Chile, Chile: CEPAL. Obtenido de http://bibspi.planejamento.gov.br/bitstream/handle/iditem/509/08\%20Cadei as\% 20produtivas. pdf? sequence $=1$

Porter, M. E. (2009). Ser Competitivo. Barcelona, España: Ediciones DEUSTO. Obtenido de: https://books.google.com.ec/books?id=CIgKoErmS_MC\&printsec=frontcover\& $\mathrm{dq}=\mathrm{ventaja}+$ competitiva + michael + Porter + pdf\&hl=es\&sa $=$ X\&ved $=0$ ahUKEwjP 6ZL5zrjbAhVDrVkKHa6CAwwQ6AEIMTAC\#v=onepage\&q\&f=false

Porter, M. \& Kramer, M. (2006). Estrategia y sociedad. Harvard Businesss School. Vol. December; pp. 1-15.

Sabino, C. (2014). El Proceso de Investigación. Guatemala: Guatemala. Episteme Editorial. Obtenido de:

https://books.google.com.ec/books?hl=en\&lr=\&id=jwejBAAAQBAJ\&oi=fnd\& $\mathrm{pg}=\mathrm{PP} 6 \& \mathrm{dq}=$ metodologia + de + investigacion\&ots $=$ WOcfvNakYD\&sig $=$ LBoLdh Ipos28cuAixMnjUIXISmk\&redir_esc $=y \# v=$ onepage\&q\&f $=$ false

Salazar, M., \& Van der Heyner, D. (2004). Metodología de análisis de cadenas productivas con equidad para la promoción del desarrollo local. Cajamarca: SNV.

Simanca, M. M., Montoya, L. A., \& Berna, C. A. (2016). Gestión del Conocimiento en Cadenas Productivas. El Caso de la Cadena Láctea en Colombia. SCIELO.

Simanca, M., Montoya, L., Bernal, A. \& Bernal, C. (2015). Gestión del Conocimiento en Cadenas Productivas. El Caso de la Cadena Láctea en Colombia. Información Tecnológica. doi:10.4067/S0718-07642016000300009 


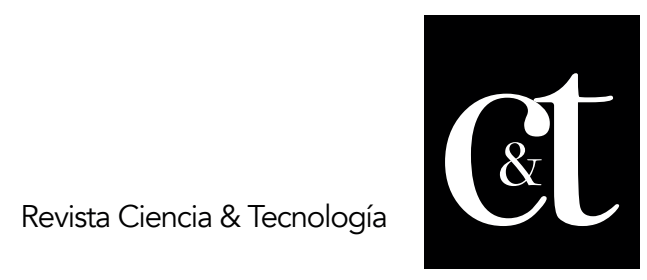

No. 23, 31 de julio de 2019

ISSN impreso: 1390 - 6321

ISSN online: 2661 - 6734

doi:http://dx.doi.org/10.4067/S0718-07642016000300009

Tamayo, C. O., \& Cepeda, D. (15 de Agosto de 2017). Sistemas de producción campesinos y gestión social del riego. Dialnet.

Tomta, D., \& Chiatchoua, C. (2009). Cadenas productivas y productividad de las Mipymes. Criterio Libre. V.11, pp. 145-164.

Torres, J., \& Jaramillo, O. (2014). Diseño y análisis del puesto de trabajo. Barranquilla: Colombia. Editorial Universidad del Valle.

Tungurahua, H. G. (5 de septiembre de 2017). http://tungurahua.gob.ec. ( Honorable Gobierno Provincial de Tungurahua,) Obtenido de http://tungurahua.gob.ec/index.php/informativo-hgpt/principales/2305-impulsoal-comercio-productor-consumidor 